Economics Letters 59(1998) 201-205

\title{
Correlation of seasonal variation and nonseasonal variation of production at the establishment level
}

\author{
Eiichi Tomiura* \\ Faculty of Economics, Shinshu University, Matsumoto City, Nagano 390, Japan
}

September 1997

\begin{abstract}
The longitudinal data of a seasonal industry reveal a positive correlation across establishments between seasonal variation and nonseasonal variation of production. Intra-industry variations are small in high seasons. As establishments with higher capacity utilization are less variable, the capacity constraint is the possible explanation.
\end{abstract}

Keywords: Seasonality; Intra-industry variation; Capacity constraint

JEL classification:D24; L11; L16

\section{Introduction}

In the study of seasonality, Beaulieu, MacKie-Mason and Miron(1992) found "a strong positive correlation across countries and industries"(p.621) between the seasonal variation and the nonseasonal variation in aggregate variables ${ }^{1}$. They also develop a model which is consistent with this "robust stylized fact"(p.635). In their model, the firm's endogenous choice of production capacity is the cause of this relation because "firms facing bigger seasonal or nonseasonal shocks choose more flexible technologies and thus are better able to respond to both kinds of shocks."(p.622) Under this hypothesis, a particular form of seasonal heteroskedasticity should be predicted in cross-section, intra-indusry variance of production. "During the low season, there will be substantially more variation in realized output than during the high season because of the effective truncation of high season output by the capacity constraint.”(p.649)

If the capacity constraint really generates this regularity, the positive correlation they found at

*phone: +81-(0)263-37-2339; fax:+81-(0)263-37-2344;e-mail: etomiura@econ.shinshu-u.ac.jp I appreciate the financial support by Grant in Aid for Scientific Research on Micro Data No. 08209202 and No. 09206205 of the Ministry of Education, Science and Culture. The access to the original micro-data file is arranged by the Ministry of International Trade and Industry and the General Coordination Agency. Yukio Uchida provided excellent research assistance. Any remaining errors are mine.

1 Many interesting regularities are documented, for example, in Miron(1996). 
the aggregate level must be directly observed at the micro level; i.e. at the individual firm, establishment, or plant level. Otherwise, we cannot exclude the possibility that the regularity at the macro level is merely a statistical artifact of aggregation. This paper investigates the relationship between seasonal variation and nonseasonal variation by employing the newly available longitudinal data of production at the establishment level in an industry.

The results from my study not only support the previous findings from the aggregate variables, but also cement their microecomic implications. Since the relatively strong positive correlation between the seasonal component and the nonseasonal component is maintained at the establishment level, we now confirm that the regularity at the aggregate level is not the statistical artifact. Besides, by exploiting the longitudinal nature of the data set, this paper also finds that an establishment with higher capacity utilization rate tends to have smaller variability in production. This finding is clearly consistent with the capacity constraint interpretation which was analyzed by simulations in Beauliue et.al.(1992). Therefore, this paper provides direct, microeconomic evidence for the correlation between seasonal variation and nonseasonal variation and suggests that the capacity choice is really the candidate explaining this relationship.

The rest of the paper has three sections. Section 2 describes the data. Section 3 reports the results of empirical studies. Section 4 concludes.

\section{Description of data}

This paper exploits the longitudinal data of production at the establishment level in an industry. As an example of the economic variables with strong seasonal cycles, this paper chooses the production of air conditioners in Japan and draws data from Current Survey of Production, which contains data including production quantity and capacity on monthly basis. To see the variations within an industry, I made access to the establishment-level micro-data file of the government and compiled it to the longitudinal form ${ }^{2}$. Due to the availability of original data files, the sample period is from January 1988 to December 1995. The data show that twenty-seven establishments produced air conditioners in Japan at least a month during the sample period. Since they operated less than two years, we exclude six of them in the study of seasonality. As a result, our sample consists of twenty-one establishments ${ }^{3}$.

2 This paper employs the micro data from Current Survey of Production (Seisan-Doutai Toukei, in Japanese), compiled by the Ministry of International Trade and Industry. The legal restriction is imposed on the direct access to individual files in original statistics. As long as one follows the specified rules on confidentiality, however, anyone can be allowed to have access to the micro-data upon the individual permission from the Ministry. The classification code in the statistics is "air conditioners" in No.2180 "Refrigerating Machines." The production quantity in this paper is defined as the number of outside unit produced. The data specially aggregated for this paper will be available upon request by the author.

3 Out of twenty-one, thirteen establishments keep producing all the months in the sample period 
The production of air conditioners in Japan is strongly seasonal due to the demand peak at the summer. $R^{2}$ is as high as 0.66 in the regression on monthly dummies alone. Table 1 summarizes the basic statistics to demonstrate that the average production variability is substantially larger across months than across years.

\section{Empirical study of seasonality in air conditioner production}

As a first step, I decompose the seasonal component from the original production data of each establishment by the regression on monthly dummies. To make comparison easier, this paper adopts the same method as Beaulieu et. al.(1992). The dependent variable is the first-difference of logarithm of production quantity. Let $q_{i t}=d \ln Q_{i t}$ and $d_{k t}$ be a dummy for month k, where $Q_{i t}$ denotes the production quantity of the establishment $\mathrm{i}(\mathrm{i}=1,2, \ldots, \mathrm{I})$ at time $\mathrm{t}(\mathrm{t}=1,2, \ldots, \mathrm{T})$.

$$
q_{i t}=\sum_{k=1}^{12} \xi_{i k} d_{k t}+\varepsilon_{i t}
$$

$\varepsilon$ is the residual term. The "seasonal" and "nonseasonal" component of production $\left(q_{i t}^{S}, q_{i t}^{N}\right)$ are defined as follows, relying on the OLS estimated coefficients $\left(\hat{\xi}_{i k}(k=1,2, \ldots, 12)\right)$ in the regression (1);

$$
\begin{aligned}
& q_{i t}^{S} \equiv \sum_{k=1}^{12} \hat{\xi}_{i k} d_{k t} \\
& q_{i t}^{N} \equiv q_{i t}-\sum_{k=1}^{12} \hat{\xi}_{i k} d_{k t}
\end{aligned}
$$

Next, I take the standard deviation of nonseasonal component and the standard deviation of seasonal component of production over time for each establishment $\left(\hat{\sigma}_{i}^{N}, \hat{\sigma}_{i}^{S}\right)^{4}$.

Based on the information thus defined, this paper conducts several experiments by regressions. First, the cross-section regression of nonseasonal standard deviation on seasonal standard deviation is conducted. Previous results suggest the positive coefficient. Second, I run the time-series regression of intra-industry standard deviation across establishments on total industry size $\left(Q_{t}\left(=\sum_{i=1}^{I} Q_{i t}\right)\right.$ ) or on monthly dummies to test the proposition that the variance in the high season is lower. Finally, the relation between the intertemporal variation of production and the capacity utilization is estimated to check the plausibility of capacity constraint interpretation. The capacity utilization rate (CU) for each establishment is calculated as follows, where $\mathrm{K}$ denotes the capacity level;

while eight establishments stop producing for some months.

${ }^{4}$ In calculating the standard deviations, the degree of freedom is adjusted taking account that the seasonals are estimated, exactly as in Beaulieu et.al.(1992). 


$$
\overline{C U}_{i}=\frac{1}{T} \sum_{t=1}^{T} \frac{Q_{i t}}{K_{i t}}
$$

The results of the regressions are reported in Table 2. All the coefficients have the signs as predicted. The $t$ value suggests that the estimated coefficient is significantly different from zero. From the result shown in the column (1), we confirm that the relation previously found by Beaulieu et. al.(1992) at the aggregate level is maintained at the establishment level. $R^{2}$ is especially high ${ }^{5}$. From the columns (2) and (3), the relation that the intra-industry variation is smaller in high season, which was suggested by Beaulieu et. al.(1992), has been provided a supportive evidence ${ }^{6}$. The result reported in the column (4) is consistent with the story that the capacity constraint causes the relation between seasonals and nonseasonals.

\section{Concluding remarks}

The use of micro data enables us to confirm that a positive correlation between the seasonal variation and the nonseasonal variation is not a statistical articaft of aggregation. The longitudinal data also succeeds in providing clear evidence for the capacity constraint explanation of this correlation. Since the data set which I employ contain shipment data as well as production data, the study of the production-smoothing model of inventory, as Ceccheti et. al.(1995) explores, will be an interesting future topic.

Although the production of air conditioners has be chosen as an example of strongly seasonal economic activities, evidence from a particular industry should be viewed as nothing more than one episode. The next step for future work must include the comparison with industries which are supposed to be nonseasonal. We expect larger responses to nonseasonal shocks, such as exchange rate depreciation, in seasonal industries due to the industrial difference in technological flexibility.

\section{References}

Beaulieu, J.J., J. MacKie-Mason, and J. Miron, 1992, Why do countries and industries with large seasonal cycles also have large business cycles? Quarterly Journal of Economics, May, 621-656

Cecchetti, S., A.Kashyap, and D.Wilcox, 1995, Do firms smooth the seasonal in production in a boom? Theory and evidence, a paper presented at the $7^{\text {th }}$ World Congress of Econometric Society Miron, J., 1996, The Economics of Seasonal Cycles (MIT Press, Cambridge)

5 The result is not affected even if we exclude eight establishments which record zero production for some months during the period.

${ }^{6}$ In the regression of production quantity level on monthly dummies, the coefficients of monthly dummies from February to July (d2,..,d7) are positive and those from August to January (d8,..,d1) are negative. 
Table 1 SUMMARY STATISTICS AT THE INDUSTRY LEVEL

\begin{tabular}{|c|c|c|c|c|}
\hline & AVERAGE & ST.DEV & MAX & MIN \\
\hline MONTH & 669,381 & 182,610 & 930,306 (June) & 378,089 (Aug.) \\
\hline YEAR & 669,381 & 109,776 & 836,912 ('91) & 526,293 ('93) \\
\hline
\end{tabular}

(NOTE) The first row corresponds to the average from 1988 to 1995 for each corresponding month. The second row corresponds to the average over twelve months for each year. The number of units produced is averaged. By letting $Q_{m}^{y}$ be the production at the month $\mathrm{m}$ in the year y, each average is defined as "MONTH" $=\frac{1}{8} \sum_{y=1988}^{1995} Q_{m}^{y}, " Y E A R "=\frac{1}{12} \sum_{m=1}^{12} Q_{m}^{y}$

Table 2 REGRESSION RESULTS

\begin{tabular}{|c|c|c|c|c|}
\hline & $(1)$ & $(2)$ & $(3)$ & $(4)$ \\
\hline DEPENDENT VARIABLE & $\hat{\sigma}_{i}^{N}$ & $\sigma_{t}$ & $\hat{\sigma}_{t}^{N}$ & $\sigma_{i}$ \\
\hline RHS VARIABLE & $\hat{\sigma}_{i}^{S}$ & $Q_{t}$ & $\mathrm{~d} 1, \mathrm{~d} 2, \ldots, \mathrm{d} 11$ & $\overline{C U}_{i}$ \\
\hline $\begin{array}{c}\text { COEFFICIENT } \\
(|\mathrm{t}|)\end{array}$ & $\begin{array}{c}1.508 \\
(11.73)\end{array}$ & $\begin{array}{c}-1.1 \mathrm{E}-6 \\
(6.05)\end{array}$ & $\begin{array}{c}\mathrm{d} 1, \ldots, \mathrm{d} 5(-) \\
\mathrm{d} 6, \ldots, \mathrm{d} 11(+)\end{array}$ & $\begin{array}{c}-0.615 \\
(1.79)\end{array}$ \\
\hline$R^{2}$ & 0.879 & 0.282 & 0.453 & 0.144 \\
\hline
\end{tabular}

(NOTE) The regression format is cross-section in (1) and (4), time-series in (2) and (3). In the column (3), only the sings of the coefficients are shown to save space. 